\title{
Research on Packaging Design Art of Elderly Products in China
}

\author{
Weiqi $\mathrm{Qi}^{1, \mathrm{a}^{*}}$ and Jing Xue $\mathrm{e}^{2, \mathrm{~b}}$ \\ ${ }^{1}$ Sichuan University of Media and Communications, Chengdu, Sichuan, 611756, China \\ ${ }^{2}$ Southwest Jiaotong University, Chengdu,Sichuan,611756,China \\ a13688418119@139.com, bjoyxuejing@sohu.com \\ * the corresponding author
}

Keywords: Elderly products; Victory characteristics; Consumer demand; Packaging; Design

\begin{abstract}
This paper expounds how to combine the physiological characteristics of old people with the elements of package design and design the packaging suitable for the elderly. In this paper, the physiological features of the elderly, such as vision, touch and memory, are analyzed, and the basic requirements for the packaging design of the aged products are revealed. According to the physiological and psychological characteristics of the elderly and the product packaging design concept centered on the elderly, the design method of packaging for aged products was established and the design proposal was put forward. Through the analysis of the characteristics of the elderly consumer demand and product packaging, and then put forward the design principle of the packaging of the elderly products. Not only broadens the designer's concept, but also provides a reference valuable for the design of enterprise's packaging products.
\end{abstract}

\section{Introduction}

According to statistics, at present, in China's population, the number of people that areover the age of 60 has reached 152 million, accounting for $10.2 \%$ of the total population, and Chinahas entered the era of aging. By 2030, China's elderly population will exceed the sum of the European population, which will be a very large figure. But there is a huge and rich consumer demand behind the huge numbers [1, 2]. This kind of change causes the old age products and the packing market to enliven gradually, then forms many gaps, the designer and the manufacturer should pay attention to the market's new trend, seize this rare opportunity [3-5].As a kind of behavior that beautifies the production and life, design is to serve the users, and to satisfy the material and spiritual needs of the users. It has to meet the specific purpose, for example, in order to improve the deficiency of a particular aspect of the product, in order to solve the trouble of people, in order to help the lives of vulnerable groups, in order to alleviate social problems. In order to make the packaging design more targeted, it is necessary to study the specific targeted groups, such as children's product packaging design, packaging design of elderly products, design of women's products and so on [6].

\section{Analysis of packaging status of elderly products}

As a developing country, The features of the population aging are the number of aged people speed up in a short time, and presents the imbalance of regional development, phase imbalance,international and special features. According to statistics, in 2015, the population aged 60 and over reached 222 million, accounting for $16.15 \%$ of the total population. It is expected that by 2020 , the elderly population will reach 248 million, aging level reached $17.17 \%$, of which 80 years old or older population will reach 30 million 670 thousand people; in 2025, the population over the age of sixty will reach 300 million, become a super old country, as shown in figure 1. This special national condition has made the development of the aged products and their packaging market in our country fail to keep up with the demand of the market development. 

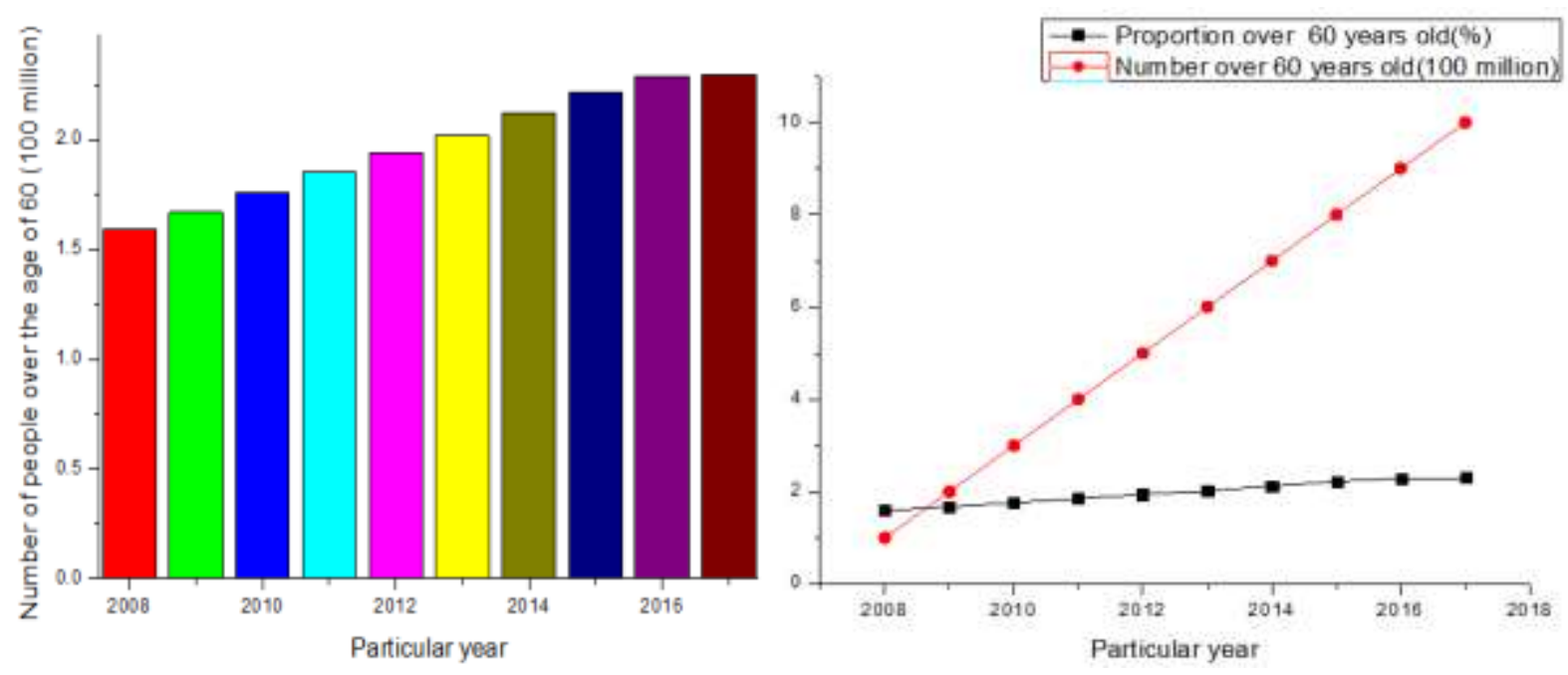

Figure 1. Population and the proportion of population over 60 years old in China in 2008-2017

With the increase of the elderly population and the aging of the population structure, it will inevitably have a profound impact on society and economy. Due to the aging of the population has deepened, directly lead to a rise in the elderly social burden coefficient in the working age population andwill inevitably increase the economic burden, promote national tax and fiscal expenditure to the implementation of the social security system, more national income will be used for social insurance and social welfare undertakings [7]. From a practical point of view, at present our country for the elderly this special consumer groups are relatively short, so the packaging industry product for the elderly is more backward, even if there are some of the packaging, its design is very simple and boring. The old people often wear a certain brand of shoes packaging as an example, the package is only a single oil cylinder cover. Only a few descriptive words such as the manufacturer, model and date of production are printed on the paper. The packaging is neither elegant nor portable. With the improvement of people's material and cultural level, the needs of the elderly are becoming more and more colorful, and the packaging of products should change accordingly. To survive and develop,enterprises need toadapt to the trend of the times. On the other hand, even though some of the old products are beautifully packaged, they are not recognized by the elderly [8].

\section{Packaging design art of elderly products}

The design is to meet a specific behavior of social needs the most reasonable under certain conditions, the elderly products packaging design should be "to the elderly", reflect the design of ethics and social responsibility. Different age and sex, the health status of the elderly also have different requirements on the packagingproduct, this chapter through the analysis of the elderly physiological and psychological and consumer psychological characteristicsputforward the design method and principle of old product packaging. According to Maslow's theory, human needs are divided into layers, and the needs of human beings are related to age and physiological and psychological conditions of human beings [9]. Therefore, analysis of the elderly packaging requirements, we must start from its physiological and psychological. Figure 2 is the art analysis of packaging design of elderly products in China, and also the main content of this chapter.

The old people easily recognize the colors and fonts of the packaging. The old man, due to aging, has lost the focus of eye lenses, and needs bifocal lenses, which are normally fixed close to $40 \mathrm{~cm}$ (reading) and $7 \mathrm{~m}$ (driving) at a distance. When the focal length is fixed, the products on the $80 \mathrm{~cm}$ shelf are difficult to recognize by the old, while the government decrees require that the written instructions on the package be detailed, which will inevitably result in smaller printed words. If you put these packages away from $40 \mathrm{~cm}$, the young people see a very clear image, and the old people look from bifocal lensesit isa blurry picture [10]. Therefore, designers can design an old product logo which is easy 
for the elderly to identify, and in its overall design, and other types of goods to form a strong contrast, so that it can quickly attract the attention of the elderly.

The old people's demand for the convenient use of the packaging molding structure. Because the elderly muscle control recession, coupled with a lot of elderly people suffering from arthritis and other diseases, which makes a lot of elderly people to open the packaging of goods is often encountered in life, such as open ham sausage packaging need a knife, use pliers to open the bottled edible oil. Encountered such a situation, on the one hand, the elderly may express dissatisfaction and anger; on the other hand, the elderly will fall into helpless inferiority. In these cases, designers should make use of the packaging structure to bring convenience to the elderly users [11]. The environment, climate and external objects should be taken as the design contents and methods. From the point of view of ergonomics, it is convenient to design the packaging structure for the elderly, and fully consider the sensory system of the old people in use. You can use a lot of shape and structure for older consumers from buying a place carrying home portable handling; easy to use and easy to open the device are closed; food bags tear, and cap to rotate and open the pressing structure to replace the convenience of these structures.

The old people's demand for packaging modeling and material safety. Because the old people's sense of touch, judgment, cognitive ability and reaction ability is suffering from a varying degrees of decline. In the packaging design of aged products, it should be noted that the packing volume should not be too heavy, and should be considered for easy lifting, pulling and taking. Meanwhile, the packing should be designed in a smooth way so as to prevent the edges and corners of the outer packing from causing personal injury. Pay attention to non-toxic, waterproof, dustproof and other features of packaging materials, through the combination of different material texture, which areeasy to use and comfortable grip, embodies the anti-skid and other useful features in the product packaging contact parts, so as to give the elderly more sense of security and comfort. In addition, pay special attention to the use of packaging materials for environmental health.

The elderly needs of the packaging to remember. Memory loss is a significant physiological feature of the elderly. According to the survey, the average age of 60 year old people aretaking 7 different medicine, we can see that the design and development of a regular reminder of the elderly bottles of medication is very necessary. This article holds that for a certain age of the elderly, often need to take some health care medicine, you can design a new type of packaging box, will be a variety of drugs at the same time installed in one boxes. The box is divided into parts according to the number of days a week, and each part is divided into 4 compartments according to the number of times taken per day. The boxes are marked with the number of weeks and the time of taking the medicine. If you need to take the medicine, you can know whether you have taken the medicine when you look at the package.

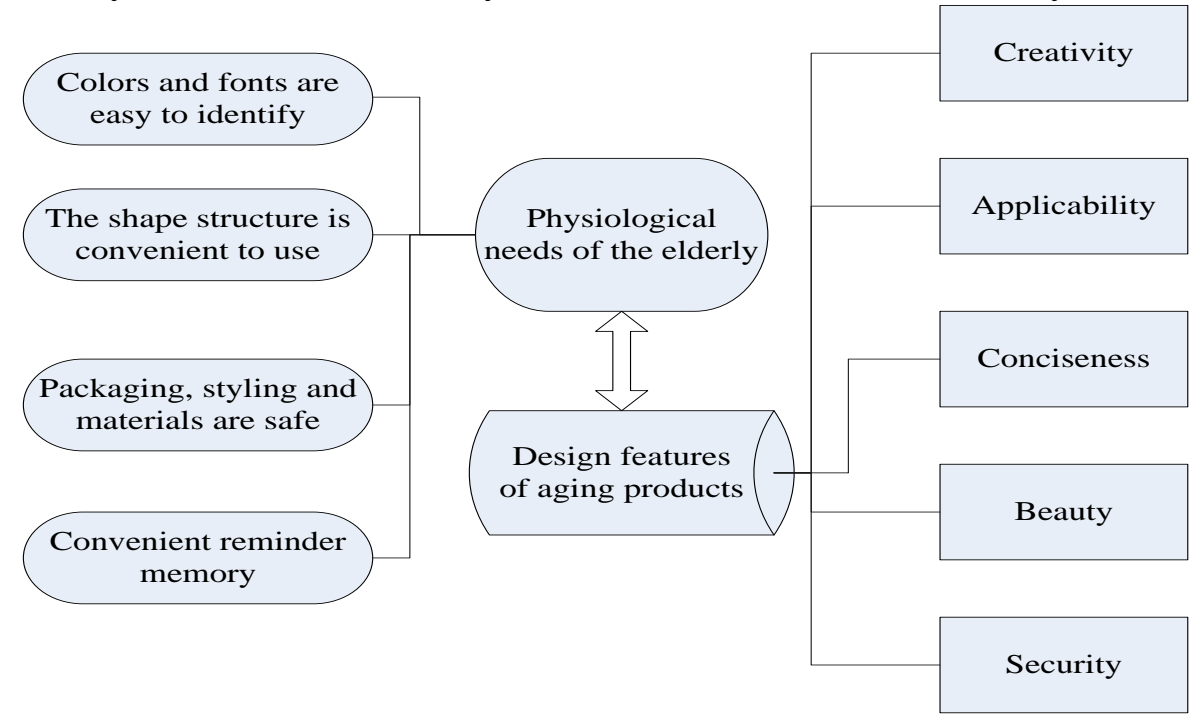

Figure 2. Art analysis of packaging design of elderly products in China 


\section{Principles of packaging design for elderly products}

In order to design a good packaging product, we should start from the consumer's point of view. Now, our targeted consumer group is the elderly, should be "elderly based", take full account of the elderly physical and psychological needs and changes to meet the increasing material and spiritual needs of the elderly. A good packageproduct should have the following characteristics:

(1) Creativity. This is the most important prerequisite for package design.

(2) Applicability. The packaging design completed by the designer must be suitable for elderlypeople. All this must be carried out around the psychological and physiological characteristics of the elderly.

(3) Conciseness. Product load information to make clear to the elderly, its role, methods of operation are simple and clear.

(4) Beauty. Any user would like to buy their products more beautiful, the elderly are no exception.

(5) Security. This is an oldpackaging product, thus the securitydesign can not be ignored.The product shouldnot only includes the non-toxic, waterproof, dustproof and other characteristics of the packaging materials, but also includes the safety of the packaging in the process of opening and using.

\section{Summary}

In essence, any product that is design to meet elderly people's needs. With the development of the times, the demand level of the elderly is becoming more and more rich, which requires designers to analyze the market when they design the packaging of the aged products, so as to meet the various needs of the elderly. Nowadays, with the deterioration of people's living environment, the problem of human sustainable development has attracted more and more attention. As is known to all, an important factor affects the environment is garbage, while the waste package occupies a considerable proportion in the garbage. Therefore, the future of the elderly product packaging should take the road of green packaging, which means not only to save energy, save materials, but also can be recycling. This not only conforms to the old man's relatively thrifty traditional habits, but also meets the requirements of modern environmental protection.

\section{References}

[1] Liu Y, Meng Y, University C M. Research on Long-term Care Insurance Law in China under the background of aging-Care Insurance Law in Japan for reference[J]. Chinese Hospitals, 2016.

[2] Zuo Q, Xian B P. The Research on the Industrial Structure Optimization and Adjustment in China under the Background of An Aging Population-Based on the Viewpoint of the Decrease in Labor Force Supply[J]. West China Finance, 2016.

[3] Zhang W. The Application of the Doctrine of the Mean Thought in Product Packaging Design[J]. Packaging Engineering, 2015.

[4] Liu F. The Design Method of Product Design for Aging People Based on Systematic Design Thoughts[J]. Packaging Engineering, 2015.

[5] Wu J. From Symbol to Image: Poetic Expression of Traditional Culture in the Modern Chinese Design Art[J]. Zhejiang Social Sciences, 2016.

[6] Liu H L. Chinese Local-style Dwelling Houses Tracery Element Embedded in the Packaging Design[J]. Packaging Engineering, 2016.

[7] Cheng S. Research on Packaging Design Strategy of Ecological Aquatic Products in Ganpo[J]. Journal of Green Science \& Technology, 2016.

[8] Zhang B. Application of Color and Graph in Packaging Design for Children's Products[C]// International Conference on Education, Language, Art and Inter-Cultural Communication. 2017.

[9] Li J. The Reflection of Traditional Chinese Characters in Packaging Design[J]. Packaging Engineering, 2015.

[10]Wang W, Zhi-Hui W U, University N F. See the Japan' s Creative Packaging Design from Excessive Decoration of Products Packaging[J]. Packaging Engineering, 2015. 
[11]Li L I. Inheritance of Folk Art Emotion Gene in Packaging Design[J]. Packaging Engineering, 2017. 